\title{
Anaplasma phagocytophilum strains from voles and shrews exhibit specific ankA gene sequences
}

\author{
Juliana Majazki ${ }^{1}$, Nicole Wüppenhorst ${ }^{1}$, Kathrin Hartelt ${ }^{2}$, Richard Birtles ${ }^{3}$ and Friederike D von Loewenich ${ }^{1 *}$
}

\begin{abstract}
Background: Anaplasma phagocytophilum is a Gram-negative bacterium that replicates obligate intracellularly in neutrophils. It is transmitted by Ixodes spp. ticks and causes acute febrile disease in humans, dogs, horses, cats, and livestock. Because A. phagocytophilum is not transmitted transovarially in lxodes spp., it is thought to depend on reservoir hosts to complete its life cycle. In Europe, A. phagocytophilum was detected in roe deer, red deer, wild boars, and small mammals. In contrast to roe deer, red deer and wild boars have been considered as reservoir hosts for granulocytic anaplasmosis in humans, dogs, and horses according to groESL- and ankA-based genotyping. A. phagocytophilum variants infecting small mammals in Europe have not been characterized extensively to date.

Results: We amplified the total ankA open reading frames of 27 strains from voles and shrews. The analysis revealed that they harboured $A$. phagocytophilum strains that belonged to a distinct newly described ankA gene cluster. Further, we provide evidence that the heterogeneity of ankA gene sequences might have arisen via recombination.
\end{abstract}

Conclusions: Based on ankA-based genotyping voles and shrews are unlikely reservoir hosts for granulocytic anaplasmosis in humans, dogs, horses, and livestock in Europe.

Keywords: Anaplasma phagocytophilum, Voles, Shrews, Genotyping, ankA gene, Recombination

\section{Background}

Anaplasma phagocytophilum is a Gram-negative bacterium that replicates obligate intracellularly in neutrophils [1]. It is tick-transmitted and causes acute febrile disease in humans [2], in companion animals such as dogs [3], horses [4], and cats [5] as well as in livestock such as sheep and cattle [6,7]. The main vector of $A$. phagocytophilum in Europe is Ixodes ricinus, whereas it is primarily transmitted by I. scapularis and I. pacificus in North America and by I. persulcatus in Asia [2].

Evidence exists that the naturally circulating $A$. phagocytophilum strains show a considerable degree of host adaptation, because they are not equally infectious for different animal species [3,7-9]. The molecular characterization using major surface protein 2 ( $m s p 2$ ) pseudogene sequences [10] as well as the ankA gene [11] has shown that strains originating from humans,

\footnotetext{
* Correspondence: friederike.loewenich@uniklinik-freiburg.de ${ }^{1}$ Institute of Medical Microbiology and Hygiene, University of Freiburg, Hermann-Herder-Strasse 11, Freiburg D-79104, Germany Full list of author information is available at the end of the article
}

dogs, and horses are homologous. Furthermore, horses and dogs are susceptible to infection with human $A$. phagocytophilum isolates [12-14].

At least in Ixodes spp. ticks A. phagocytophilum is not transmitted transovarially [15]. Therefore, it is thought to depend on reservoir hosts to complete its life cycle. In North America, based on molecular characterization and experimental infections small mammals such as whitefooted mice [16,17], chipmunks $[18,19]$, and squirrels [19] were reported as probable reservoirs for granulocytic anaplasmosis in humans, horses, and dogs. In contrast, the impact of white-tailed deer and woodrats was questioned $[18,20,21]$. In Europe, A. phagocytophilum was detected amongst others in roe deer [22,23], red deer [23], wild boars [24], hedgehogs [25], and other small mammals [26].

The 16S rRNA gene has been used most often for strain characterization. However, it was shown that it is not informative enough to delineate distinct $A$. phagocytophilum genotypes [11,27-29]. Based on groESL and ankA gene sequences red deer $[11,30]$ and wild boar $[31,32]$ were considered as reservoir hosts for granulocytic anaplasmosis in humans, dogs, and horses. In contrast, roe deer harboured 
A. phagocytophilum strains which mostly belonged to clearly separated groESL [30] and ankA [11] gene clusters.

Apart from using the 16S rRNA gene the A. phagocytophilum variants infecting small mammals in Europe have not been typed extensively to date. We therefore amplified the total ankA open reading frame (ORF) of 27 strains from voles and shrews captured in Germany as well as the UK and compared them to 221 ankA sequences determined earlier [11,27]. We here show that they harboured $A$. phagocytophilum strains that belonged to a distinct newly described $a n k A$ gene cluster. Therefore, voles and shrews are unlikely reservoir hosts for granulocytic anaplasmosis in humans, dogs, horses, and livestock in Europe.

\section{Methods}

\section{Samples}

27 A. phagocytophilum positive DNA samples from voles and shrews were investigated. 22 had been prepared earlier from the lung of voles captured in Germany [33]. Five had been purified from the blood of two voles [34] and three shrews [35] from the United Kingdom. The $16 \mathrm{~S}$ rRNA and ankA gene sequences obtained here were compared to 221 sequences from humans, a great variety of animals, and I. ricinus ticks from previous studies $[11,27]$. Furthermore, seven additional samples from three humans, one dog, one horse, one cow, and one sheep were included. Table 1 shows host species and geographic origin of the samples.

\section{PCR analyses and sequencing}

1 to $2 \mu \mathrm{l}$ of DNA were used as template in a $50 \mu \mathrm{l}$ reaction mixture containing $50 \mathrm{mM} \mathrm{KCl}, 20 \mathrm{mM}$ Tris- $\mathrm{HCl}$ (pH 8.4), $2 \mathrm{mM} \mathrm{MgCl}_{2}, 0.2 \mathrm{mM}$ desoxynucleoside triphosphates, $0.4 \mu \mathrm{M}$ of each primer, and $0.2 \mu \mathrm{l}$ (1U) of Taq DNA Polymerase (Invitrogen, Karlsruhe, Germany). PCRs were performed using the GeneAmp PCR System 9700 (Applied Biosystems, Darmstadt, Germany) under the following conditions: initial denaturation at $94^{\circ} \mathrm{C}$ for 3 min, 40 cycles consisting of denaturation at $94^{\circ} \mathrm{C}$ for $30 \mathrm{~s}$, annealing at the predicted melting temperature of the primers minus $4^{\circ} \mathrm{C}$ for $30 \mathrm{~s}$, extension at $72^{\circ} \mathrm{C}$ for $30 \mathrm{~s}$ per amplification of $500 \mathrm{bp}$, and a final extension at $72^{\circ} \mathrm{C}$ for $10 \mathrm{~min}$. Nested PCR amplification and sequencing of the $A$. phagocytophilum $16 \mathrm{~S}$ rRNA gene $[27,38]$ and of the $a n k A$ gene clusters I [39] and IV [11] were performed as described previously. Nested PCR amplification and sequencing of the ankA gene cluster $\mathrm{V}$ was achieved as shown in Additional file 1: Table S1. The sequence of the complete ORF was obtained by assembling the sequences of the six nested PCR products. Nucleotide sequences of primers (Metabion, Martinsried, Germany) are summarized in Additional file 2: Table S2. Nested PCR products were directly sequenced bidirectionally using a 3130 Genetic Analyzer (Applied
Table 1 Host species and geographic origin of

A. phagocytophilum positive samples $(n=34)$

\begin{tabular}{|c|c|c|c|}
\hline Sample & Origin & Sample & Origin \\
\hline Myodes glareolus & & Microtus arvalis & \\
\hline 2/99 & Germany & 79/99 & Germany \\
\hline $23 / 99$ & Germany & $151 / 99$ & Germany \\
\hline $42 / 99$ & Germany & 220/99 & Germany \\
\hline $92 / 99$ & Germany & Sorex araneus & \\
\hline 106/99 & Germany & S1 & UK \\
\hline 129/99 & Germany & S2 & UK \\
\hline 159/99 & Germany & S3 & UK \\
\hline $240 / 00$ & Germany & Homo sapiens & \\
\hline $241 / 00$ & Germany & Human 96HE27 & USA \\
\hline $252 / 00$ & Germany & Human 98HE4 & USA \\
\hline 278/00 & Germany & Human HGE-1 ${ }^{*}$ & USA \\
\hline 289/00 & Germany & Canis lupus familiaris & \\
\hline $331 / 00$ & Germany & Dog Martin ${ }^{* *}$ & USA \\
\hline $338 / 00$ & Germany & Equus caballus & \\
\hline $354 / 00$ & Germany & Horse 32 FR & Switzerland \\
\hline $362 / 00$ & Germany & Bos taurus & \\
\hline $414 / 00$ & Germany & Cow A262 & Germany \\
\hline $426 / 00$ & Germany & Ovis aries & \\
\hline $523 / 00$ & Germany & sheep F1480 & Germany \\
\hline \multicolumn{4}{|l|}{ Microtus agrestis } \\
\hline F1 & UK & & \\
\hline F6 & UK & & \\
\hline
\end{tabular}

${ }^{*}[36],{ }^{* *}[37]$.

Biosystems) and the BigDye Terminator v3.1 Cycle Sequencing Kit (Applied Biosystems).

\section{Data analysis}

Sequences were edited and assembled with the SeqMan program of the DNASTAR package (Lasergene, Madison, WI). For phylogenetic analysis of the $16 \mathrm{~S}$ rRNA or ankA gene sequences the program MEGA 5.1 [40] was used. Sequences were aligned by ClustalW applying the IUB matrix (16S rRNA gene) or codon-aligned applying the PAM (Dayhoff) matrix. Tree construction was achieved by the neighbor-joining method with the complete deletion option using the Jukes-Cantor matrix for nucleotide sequences and the PAM (Dayhoff) matrix for protein sequences, respectively. Bootstrap analysis was conducted with 1,000 replicates. Average distances within and net average distances between ank $A$ gene clusters were computed using the same parameters as for tree construction. Protein sequences were analyzed for Pfam domain matches (http://pfam.sanger.ac.uk/) and for tyrosine kinase group phosphorylation sites (http://scansite. mit.edu/). Nucleotide consensus sequences were calculated 
for each ankA gene cluster with consensus maker v2.0.0 using the most common character and breaking ties with IUPAC characters (http://www.hiv.lanl.gov/content/sequence/HIV/HIVTools.html). The consensus sequences were codon-aligned by ClustalW applying the PAM (Dayhoff) matrix. The alignment was analyzed for recombination by Recco [41] with the Hamming mutation cost matrix and gap extension costs of 0.2 . Events with seq $p$-values of $<0.5$ and savings $\geq 5$ were regarded as significant.

\section{Accession numbers}

GenBank nucleotide accession numbers of 16S rRNA and ank $A$ gene sequences are shown in Table 2.

\section{Results}

\section{S rRNA gene sequences}

Seven of the 16S rRNA gene sequences from voles contained ambiguous nucleotides, indicating multiple infections with several 16S rRNA genotypes, a phenomenon that was observed already earlier in animal and tick samples [11,27]. 14 of the 27 small mammals (11 voles and three shrews) harboured an $A$. phagocytophilum variant identical to [GenBank: M73220]. This genotype is widespread mainly in ruminants, but was also detected in voles and shrews [34,35,42]. Two $16 \mathrm{~S}$ rRNA gene sequences were identical to [GenBank: AY082656] that

Table 2 GenBank nucleotide accession numbers

\begin{tabular}{|c|c|c|c|c|c|}
\hline Sample & $16 \mathrm{~S}$ rRNA & ankA & Sample & 16S rRNA & ankA \\
\hline Voles & & & Voles & & \\
\hline 2/99 & KC740418 & KC740451 & $426 / 00$ & KC740435 & KC740468 \\
\hline 23/99 & KC740419 & KC740452 & $523 / 00$ & KC740436 & KC740469 \\
\hline $42 / 99$ & KC740420 & KC740453 & $\mathrm{F} 1$ & KC740437 & KC740470 \\
\hline 79/99 & KC740439 & KC740472 & F6 & KC740438 & KC740471 \\
\hline $92 / 99$ & KC740421 & KC740454 & Shrews & & \\
\hline 106/99 & KC740422 & KC740455 & S1 & KC740442 & KC740475 \\
\hline 129/99 & KC740423 & KC740456 & S2 & KC740443 & KC740476 \\
\hline $151 / 99$ & KC740440 & KC740473 & S3 & KC740444 & KC740477 \\
\hline 159/99 & KC740424 & KC740457 & Humans & & \\
\hline $220 / 99$ & KC740441 & KC740474 & Human 96HE27 & KC740446 & KC740478 \\
\hline $240 / 00$ & KC740425 & KC740458 & Human 98HE4 & KC740447 & KC740479 \\
\hline $241 / 00$ & KC740426 & KC740459 & Human HGE-1 & KC740445 & KC740480 \\
\hline $252 / 00$ & KC740427 & KC740460 & Dog & & \\
\hline $278 / 00$ & KC740428 & KC740461 & Dog Martin & KC740448 & KC740481 \\
\hline $289 / 00$ & KC740429 & KC740462 & Horse & & \\
\hline $331 / 00$ & KC740430 & KC740463 & Horse 32 FR & JN247407 & JN247406 \\
\hline $338 / 00$ & KC740431 & KC740464 & Cow & & \\
\hline $354 / 00$ & KC740432 & KC740465 & Cow A262 & KC740449 & KC740482 \\
\hline $362 / 00$ & KC740433 & KC740466 & Sheep & & \\
\hline $414 / 00$ & KC740434 & KC740467 & Sheep F1480 & KC740450 & KC740483 \\
\hline
\end{tabular}

was found in voles in the United Kingdom [43], whereas two matched [GenBank: GU236577] originating from red deer in Germany [11]. Additionally, one vole was infected with an $A$. phagocytophilum variant identical to [GenBank: AY281785] and one with a new variant, respectively.

\section{ank $A$ sequences}

Due to the pronounced dissimilarity of the ankA gene from voles and shrews to the known ankA gene clusters I, II, III, and IV described earlier [11,27], a new set of primers had to be developed for amplification and sequencing of the complete ORF (Additional file 1: Table $\mathrm{S} 1$ ). Despite the ankA sequence from one sheep that belonged to cluster IV, all other six samples from humans and animals analysed during this study were part of cluster I. The obtained ankA gene sequences from voles and shrews were $99.8 \%$ identical to each other at the nucleotide level and $99.6 \%$ similar at the protein level. The comparison to 221 sequences (12 from humans, 43 from dogs, 10 from horses, two from cats, 53 from sheep, four from cattle, 47 from roe deer, 12 from red deer, 15 from European bison, 23 from $I$. ricinus ticks) described earlier $[11,27]$ indicated that the 27 samples from voles and shrews belonged to a new ankA gene cluster $\mathrm{V}$ and revealed nucleotide identities of $59.6 \%$ to $68.1 \%$ and amino acid similarities of $36.6 \%$ to $51.6 \%$ to the known clusters (Table 3 ). The sequences of $a n k A$ gene cluster $\mathrm{V}$ showed the lowest identities and similarities to all other ank $A$ gene clusters indicating that they were most distantly related. The sequences most closely related to ankA gene cluster $\mathrm{V}$ were those from ankA gene cluster IV. However, their identity at the nucleotide level was limited to $68.1 \%$ and their similarity at the amino acid level to $51.6 \%$ (Table 3).

A search against the Pfam domain database demonstrated that all AnkA sequences from voles and shrews contained ankyrin repeats. Furthermore, multiple tyrosine phosphorylation sites were predicted by Scansite (http:// scansite.mit.edu/) at their C-terminal end, one of them displaying a classical EPIYA motif [44]. As described for AnkA clusters I and IV [11], the abundant tyrosine

Table 3 Net average identities* and similarities** between the different ankA gene clusters in percent

\begin{tabular}{lccccc}
\hline & Cluster I & Cluster II & Cluster III & Cluster IV & Cluster V \\
\hline Cluster I & & 85.4 & 74.6 & 69.6 & 61.3 \\
Cluster II & 78.4 & & 83.3 & 73.5 & 63.0 \\
Cluster III & 60.5 & 71.2 & & 65.7 & 59.6 \\
Cluster IV & 59.8 & 63.3 & 48.3 & & 68.1 \\
Cluster V & 45.0 & 44.7 & 36.6 & 51.6 & \\
\hline
\end{tabular}

${ }^{*}$ At the nucleotide level (roman), **at the protein level (italics). 
Figure 1 Phylogenetic tree of the $16 \mathrm{~S}$ rRNA (a) and ankA (b) gene sequences inferred using the neighbor-joining method. Only bootstrap values exceeding $95 \%$ are shown. The scale bar indicates the number of nucleotide substitutions per site.

(a) Sequences with ambiguous nucleotides were not included. The final data set contained 497 positions. (b) Only bootstrap values of major branches are shown. The final data set contained 2947 positions. Roman numerals indicate ankA gene clusters. Symbols: (light green circle) dog, (red circle) human, (light blue circle) horse, (yellow circle) cat, (inverted blue triangle) sheep, (inverted gray triangle) bison, (inverted pink triangle) cow, (orange diamond) red deer, (brown diamond) roe deer, (inverted blue green triangle) vole/ shrew, (inverted black triangle) tick.

phosphorylation sites seemed to be arisen by duplication of direct repeats (Additional file 3: Figure S1).

\section{Phylogenetic analysis}

A neighbor-joining tree was constructed from the 34 ankA gene sequences obtained during this study and 221 sequences (12 from humans, 43 from dogs, 10 from horses, two from cats, 53 from sheep, four from cattle, 47 from roe deer, 12 from red deer, 15 from European bison, 23 from $I$. ricinus ticks) described earlier. As shown in Figure 1b, the A. phagocytophilum strains from voles and shrews were located on a distinct major branch that was supported by a high bootstrap value of $99 \%$. As described previously [11], sequences from humans, dogs, horses, and cats were found exclusively in ankA gene cluster I. Sequences from sheep, cattle, red deer, and European bison were more heterogenous and belonged with the exception of one red deer sequence to ankA gene clusters I and IV. In contrast, sequences from roe deer were almost exclusively found in ankA gene clusters II and III. With the exception of ankA gene clusters III and V, sequences from I. ricinus ticks were scattered around the tree as expected. Using AnkA amino acid sequences similar results were obtained (data not shown). In contrast, on a tree calculated from the $16 \mathrm{~S}$ rRNA gene sequences, no clear clustering was observed (Figure 1a).

\section{Recombination analysis}

It is possible that the striking diversity of ankA gene sequences could have developed via recombination. To test this hypothesis, we generated nucleotide consensus sequences for each ankA gene cluster. A codon-based alignment of the five consensus sequences was created and analyzed applying the Recco method [41]. Because the sequences contained many repeats near their 3' ends, the alignment was uncertain in the respective region and contained many gaps. Recco is subject to bias when analysing alignments with large gaps. We therefore further analyzed alignments without repeats as well as alignments without repeats and without any gaps. The results were compared to the analysis including repeats 
and all gaps. Whilst there was a tendency for Recco to report more and possibly spurious recombination events in the alignment containing repeats and gaps, we could confirm several recombination events with high confidence. Figure 2 shows the conservative solutions from the analysis without repeats and gaps. Each solution is defined by the calculated recombination breakpoints and the sequence most similar to the putative recombinant between the breakpoints.

\section{Discussion}

In Europe, the reservoir hosts for A. phagocytophilum have not been clearly defined to date. The molecular characterization of $A$. phagocytophilum strains using groESL and ank $A$ gene sequences revealed that red deer $[11,30]$ and wild boar [31,32] might harbour variants that cause granulocytic anaplasmosis in humans, dogs, and horses. Small mammals were considered as reservoir hosts too, but it was shown that voles were infected with $m s p 4$ genotypes that differed from those of I. ricinus ticks [34]. Because $I$. ricinus is the main vector of granulocytic anaplasmosis in humans and domestic animals in Europe [2], voles rather seem to be involved in a separate enzootic cycle probably with I. trianguliceps as tick vector [34]. This is in line with our observation that voles and shrews harboured $A$. phagocytophilum strains that belonged to a newly defined distinct ank $A$ gene cluster. Interestingly, we did not find sequences from I. ricinus ticks to cluster with those from voles and shrews supporting the hypothesis that $A$. phagocytophilum strains circulating in these small rodents are part of a completely separate ecology [34]. Similarly, the groESL variants in voles and shrews from the Asian part of Russia were found to be clearly separated phylogenetically from all other analyzed strains [42]. This is in contrast to the USA, where small rodents such as the white-footed mouse appear to be reservoir hosts for granulocytic anaplasmosis [16,17]. Our results from the ankA-based phylogeny indicate that voles and shrews harbour A. phagocytophilum strains that might not be infectious for humans, dogs, horses, and livestock. However, other rodents species apart from those investigated here, could serve as reservoir hosts in Europe.

The AnkA protein is suggested to be secreted into host cells via the VirB/VirD-dependent type IV secretion system (T4SS) of A. phagocytophilum [45,46]. After translocation it is tyrosine phosphorylated and thought to disturb host cell signalling via protein-protein interactions mediated by its ankyrin repeats $[45,46]$. At its Cterminal end AnkA typically contains one classical EPIYA and multiple EPIYA-related motifs $[11,47]$ that undergo tyrosine phosphorylation [47]. EPIYA motifs of bacterial effector proteins often show numerous duplications [44]. We described this phenomenon before especially for AnkA clusters I and IV [11] and show here that this is also true for the AnkA cluster V associated with voles and shrews (Additional file 3: Figure S1).

For the effector protein CagA of Helicobacter pylori, it was shown that its EPIYA motifs expanded via point mutation and recombination [48]. Our analysis of the

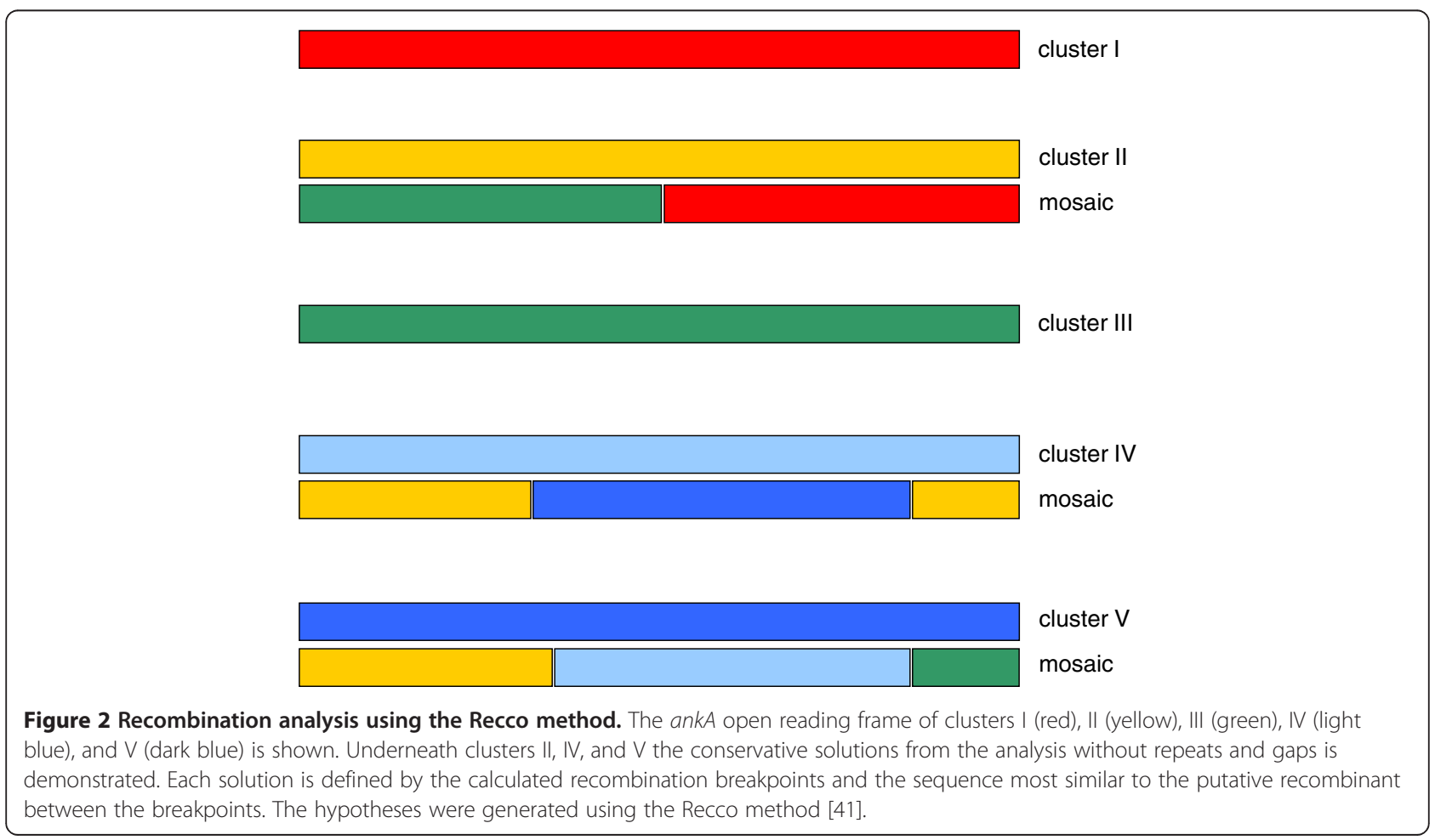


five ankA consensus sequences revealed that the marked diversity of AnkA could have arisen via recombination as well (Figure 2). However, it was not possible to determine which sequences were the ancestral ones. It has been suggested that the diversification of EPIYA motifs may lead to altered or extended target-protein binding capacities [44]. Therefore, a specific AnkA could mediate a distinct host tropism of a particular A. phagocytophilum isolate and be involved in host adapation. Accordingly, variability between strains from different host species was found mainly in the surface-exposed components of the T4SS of A. phagocytophilum [49].

If the ankA gene is indeed involved in host adaptation driven by recombination, the ankA-based phylogeny could be disturbed by the fact that one single recombination event can introduce multiple nucleotide exchanges at once. Therefore, other more conserved loci should be used to proof the phylogenetic separation of $A$. phagocytophilum strains from voles and shrews described here. Nevertheless, their marked dissimilarity to all other strains investigated, indicates a long evolutionary distance. As sequence data alone are not able to prove different biological strain properties, in vivo experiments should address whether $A$. phagocytophilum isolates from voles and shrews are infectious for humans, dogs, horses, and livestock.

Although there might be some sampling error in our data set, voles and shrews are unlikely reservoir hosts for granulocytic anaplasmosis in humans, dogs, horses, and livestock in Europe based on ankA genotyping.

\section{Conclusions}

Voles and shrews harbour A. phagocytophilum strains that contain ankA gene sequences belonging to the newly described cluster $\mathrm{V}$ that might have arisen via recombination. Because cluster $\mathrm{V}$ ankA sequences were restricted to voles and shrews, they are unlikely to serve as reservoir hosts for granulocytic anaplasmosis in humans, dogs, horses, and livestock in Europe.

\section{Consent}

For Germany, permission to trap rodents using snap traps was given by the District Government Stuttgart, Germany [50]. For the United Kingdom, protocols for the handling and sampling of wild small mammals were approved by the University of Liverpool Committee on Research Ethics and were conducted in compliance with the terms and conditions of licenses awarded under the UK Government Animals (Scientific Procedures) Act, 1986 [34].

The samples of human and domestic animal origin were obtained as part of routine diagnostic evaluation. Informed consent was obtained from the patients and owners, respectively. Human samples 96 HE27 and 98 HE4 were kindly provided by Stephen J. Dumler (The Johns Hopkins
School of Medicine, Baltimore, MD), human HGE-1 [36] and dog Martin [37] samples by Ulrike G. Munderloh (University of Minnesota, St. Paul, MN), horse sample 32 FR by Daniel Schaarschmidt-Kiener (Laboratory at Zugersee, Hünenberg, Switzerland) and cow A262 and sheep F1480 samples by Martin Ganter (University of Veterinary Medicine, Hannover, Germany).

\section{Availability of supporting data}

All supporting data are included as additional files.

\section{Additional files}

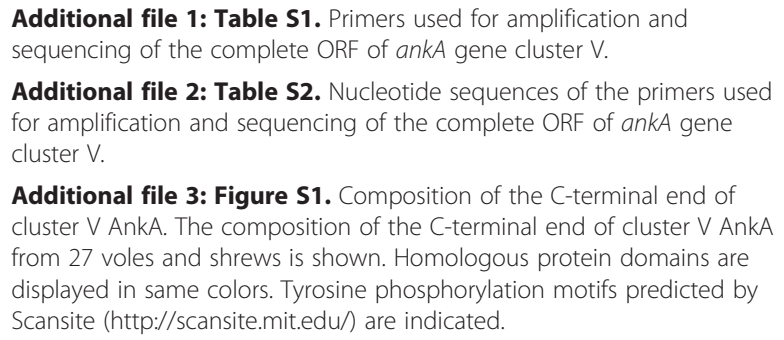

Additional file 2: Table S2. Nucleotide sequences of the primers used for amplification and sequencing of the complete ORF of ankA gene cluster $V$.

Additional file 3: Figure S1. Composition of the C-terminal end of cluster $\vee$ AnkA. The composition of the C-terminal end of cluster $\vee$ AnkA from 27 voles and shrews is shown. Homologous protein domains are displayed in same colors. Tyrosine phosphorylation motifs predicted by Scansite (http://scansite.mit.edu/) are indicated.

\section{Competing interests}

The authors declare that they have no competing interests.

\section{Authors' contributions}

$\mathrm{KH}$ and $\mathrm{RB}$ did the sampling of the small mammal material and isolated the DNA. JM, NW, and FDVL performed DNA amplification and sequencing. FDVL carried out the data analysis and drafted the manuscript. The manuscript was critically read by JM, NW, KH and RB. All authors approved its final version.

\section{Acknowledgements}

The authors are grateful to Jochen Maydt (London, United Kingdom) for his generous help with the recombination analysis. The article processing charge was funded by the German Research Foundation (DFG) and the Albert-Ludwigs-University Freiburg in the funding programme Open Access Publishing.

\section{Author details}

Institute of Medical Microbiology and Hygiene, University of Freiburg Hermann-Herder-Strasse 11, Freiburg D-79104, Germany.

${ }^{2}$ Baden-Wuerttemberg State Health Office, District Government Stuttgart, Nordbahnhofstrasse 135, Stuttgart D-70191, Germany. ${ }^{3}$ School of Environment and Life Sciences, University of Salford, The Crescent, Salford M5 4WT, UK

Received: 10 May 2013 Accepted: 25 November 2013 Published: 28 November 2013

\section{References}

1. Rikihisa Y: Mechanisms of obligatory intracellular infection with Anaplasma phagocytophilum. Clin Microbiol Rev 2011, 24:469-489.

2. Ismail N, Bloch KC, McBride JW: Human ehrlichiosis and anaplasmosis. Clin Lab Med 2010, 30:261-292.

3. Carrade DD, Foley JE, Borjesson DL, Sykes JE: Canine granulocytic anaplasmosis: a review. J Vet Intern Med 2009, 23:1129-1141.

4. Madigan JE, Pusterla N: Ehrlichial diseases. Vet Clin N Am Equine Pract 2000, 16:487-499.

5. Little SE: Ehrlichiosis and anaplasmosis in dogs and cats. Vet Clin North Am Small Anim Pract 2010, 40:1121-1140.

6. Stuen S: Anaplasma phagocytophilum - the most widespread tick-borne infection in animals in Europe. Vet Res Commun 2007, 31(Suppl. 1):79-84 
7. Woldehiwet Z: The natural history of Anaplasma phagocytophilum Vet Parasitol 2010, 167:108-122

8. Rar V, Golovljova I: Anaplasma, Ehrlichia, and "Candidatus Neoehrlichia" bacteria: pathogenicity, biodiversity, and molecular genetic characteristics, a review. Infect Genet Evol 2011, 11:1842-1861.

9. Jin H, Wei F, Liu Q, Qian J: Epidemiology and control of human granulocytic anaplasmosis: a systematic review. Vector Borne Zoonotic Dis 2011, 12:269-274

10. Foley JE, Nieto NC, Barbet A, Foley P: Antigen diversity in the parasitic bacterium Anaplasma phagocytophilum arises from selectivelyrepresented, spatially clustered functional pseudogenes. PLoS One 2009, 4:e8265.

11. Scharf W, Schauer S, Freyburger F, Petrovec M, Schaarschmidt-Kiener D, Liebisch G, Runge M, Ganter M, Kehl A, Dumler JS, et al: Distinct host species correlate with Anaplasma phagocytophilum ankA gene clusters. J Clin Microbiol 2011, 49:790-796.

12. Barlough JE, Madigan JE, DeRock E, Dumler JS, Bakken JS: Protection against Ehrlichia equi is conferred by prior infection with the human granulocytotropic Ehrlichia (HGE agent). J Clin Microbiol 1995, 33:3333-3334

13. Pusterla N, Pusterla JB, Braun U, Lutz H: Experimental cross-infections with Ehrlichia phagocytophila and human graunlocytic ehrlichia-like agent in cows and horses. Vet Rec 1999, 145:311-314.

14. Scorpio DG, Dumler JS, Barat NC, Cook JA, Barat CE, Stillman BA, DeBisceglie KC, Beall MJ, Chandrashekar R: Comparative strain analysis of Anaplasma phagocytophilum infection and clinical outcomes in a canine model of granulocytic anaplasmosis. Vector Borne Zoonotic Dis 2011, 11:223-229.

15. Ogden NH, Bown K, Horrocks BK, Woldehiwet Z, Bennett M: Granulocytic ehrlichia infection in ixodid ticks and mammals in woodlands and uplands of the U.K. Med Vet Entomol 1998, 12:423-429.

16. Telford SRI, Dawson JE, Katavolos P, Warner CK, Kolbert CP, Persing DH: Perpetuation of the agent of human granulocytic ehrlichiosis in a deer tick-rodent cycle. Proc Natl Acad Sci U S A 1996, 93:6209-6214.

17. Stafford KCI, Massung RF, Magnarelli LA, IJdo JW, Anderson JF: Infection with agents of human granulocytic ehrlichiosis, Lyme disease, and babesiosis in wild white-footed mice (Peromyscus leucopus) in Connecticut. J Clin Microbiol 1999, 37:2887-2892.

18. Foley JE, Nieto NC, Massung R, Barbet A, Madigan J, Brown RN: Distinct ecologically relevant strains of Anaplasma phagocytophilum. Emerg Infect Dis 2009, 15:842-843.

19. Rejmanek D, Bradburd G, Foley J: Molecular characterization reveals distinct genospecies of Anaplasma phagocytophilum from diverse North American hosts. J Med Microbiol 2012, 61:204-212.

20. Massung RF, Courtney JW, Hiratzka SL, Pitzer VE, Smith G, Dryden RL: Anaplasma phagocytophilum in white-tailed deer. Emerg Infect Dis 2005, 11:1604-1606.

21. Massung RF, Priestley RA, Miller NJ, Mather TN, Levin ML: Inability of a variant strain of Anaplasma phagocytophilum to infect mice. J Infect Dis 2003, 188:1757-1763.

22. Alberdi MP, Walker AR, Urquhart KA: Field evidence that roe deer (Capreolus capreolus) are a natural host for Ehrlichia phagocytophila. Epidemiol Infect 2000, 124:315-323.

23. Petrovec M, Bidovec A, Sumner JW, Nicholson WL, Childs JE, Avsic Zupanc T: Infection with Anaplasma phagocytophila in cervids from Slovenia: evidence of two genotypic lineages. Wien Klin Wochenschr 2002, 114:641-647.

24. Petrovec M, Sixl W, Schweiger R, Mikulasek S, Lebeth E, Wüst G, Marth E, Strasek K, Stünzner D, Avsic Zupanc T: Infections of wild animals with Anaplasma phagocytophila in Austria and the Czech Republic. Ann N Y Acad Sci 2003, 990:103-106

25. Skuballa J, Petney T, Pfäffle M, Taraschewski H: Molecular detection of Anaplasma phagocytophilum in the European hedgehog (Erinaceus europaeus) and its ticks. Vector Borne Zoonotic Dis 2010, 10:1055-1057.

26. Liz JS, Anderes L, Sumner JW, Massung RF, Gern L, Rutti B, Brossard M: PCR detection of granulocytic ehrlichiae in Ixodes ricinus ticks and wild small mammals in western Switzerland. J Clin Microbiol 2000, 38:1002-1007.

27. von Loewenich FD, Baumgarten BU, Schröppel K, Geißdörfer W, Röllinghoff M, Bogdan C: High diversity of ankA sequences of Anaplasma phagocytophilum among Ixodes ricinus ticks in Germany. J Clin Microbiol 2003, 41:5033-5040.

28. Bown KJ, Lambin X, Ogden NH, Petrovec M, Shaw SE, Woldehiwet Z, Birtles $\mathrm{RJ}$ : High-resolution genetic fingerprinting of European strains of Anaplasma phagocytophilum by use of multilocus variable-number tandem-repeat analysis. J Clin Microbiol 2007, 45:1771-1776.
29. Casey AN, Birtles RJ, Radford AD, Bown KJ, French NP, Woldehiwet Z, Ogden NH: Groupings of highly similar major surface protein (p44)encoding paralogues: a potential index of genetic diversity amongst isolates of Anaplasma phagocytophilum. Microbiology 2004, 150:727-734

30. Rymaszewska A: Divergence within the marker region of the groESL operon in Anaplasma phagocytophilum. Eur I Clin Microbiol Infect Dis 2008, 27:1025-1036.

31. Strasek Smrdel K, Bidovec A, Malovrh T, Petrovec M, Duh D, Avsic Zupanc T: Detection of Anaplasma phagocytophilum in wild boar in Slovenia. Clin Microbiol Infect 2008, 15:50-52.

32. Michalik J, Stańczak J, Cieniuch S, Racewicz M, Sikora B, Dabert M: Wild boars as hosts of human-pathogenic Anaplasma phagocytophilum variants. Emerg Infect Dis 2012, 18:998-1001.

33. Hartelt K, Pluta S, Oehme R, Kimmig P: Spread of ticks and tick-borne diseases in Germany due to global warming. Parasitol Res 2008, 103:S109-S116.

34. Bown KJ, Lambin X, Ogden NH, Begon M, Telford G, Woldehiwet Z, Birtles RJ: Delineating Anaplasma phagocytophilum ecotypes in coexisting, discrete enzootic cycles. Emerg Infect Dis 2009, 15:1948-1954.

35. Bown KJ, Lambin X, Telford G, Heyder-Bruckner D, Ogden NH, Birtles RJ: The common shrew (Sorex araneus): a neglected host of tick-borne infections? Vector Borne Zoonotic Dis 2011, 11:947-953.

36. Goodmann JL, Nelson C, Vitale B, Madigan JE, Dumler JS, Kurtti TJ, Munderloh UG: Direct cultivation of the causative agent of human granulocytic ehrlichiosis. N Engl J Med 1996, 334:209-215.

37. Munderloh UG, Jauron SD, Fingerle V, Leitritz L, Hayes SF, Hautman JM, Nelson CM, Huberty BW, Kurtti TJ, Ahlstrand GG, et al: Invasion and intracellular development of the human granulocytic ehrlichiosis agent in tick cell culture. J Clin Microbiol 1999, 37:2518-2524.

38. Massung RF, Slater K, Owens JH, Nicholson WL, Mather TN, Solberg VB, Olson JG: Nested PCR assay for detection of granulocytic ehrlichiae. J Clin Microbiol 1998, 36:1090-1095.

39. Massung RF, Owens JH, Ross D, Reed KD, Petrovec M, Bjöersdorff A, Coughlin RT, Beltz GA, Murphy Cl: Sequence analysis of the ank gene of granulocytic Ehrlichiae. J Clin Microbiol 2000, 38:2917-2922.

40. Tamura K, Peterson D, Peterson N, Stecher G, Nei M, Kumar S: MEGA5: molecular evolutionary genetics analysis using maxium likelihood, evolutionay distance, and maximum parsimony methods. Mol Biol Evol 2011, 28:2731-2739.

41. Maydt J, Lengauer T: Recco: recombination analysis using cost optimization. Bioinformatics 2006, 22:1064-1071.

42. Rar VA, Epikhina TI, Livanova NN, Panov W, Doroschenko EK, Pukhovskaya NM, Vysochina NP, Ivanov LI: Genetic variability of Anaplasma phagocytophilum in Ixodes persulcatus ticks and small mammals in the Asian part of Russia. Vector Borne Zoonotic Dis 2011, 11:1013-1021.

43. Bown K, Begon M, Bennett M, Woldehiwet Z, Ogden NH: Seasonal dynamics of Anaplasma phagocytophila in a rodent-tick (Ixodes trianguliceps) system, United Kingdom. Emerg Infect Dis 2003, 9:63-70.

44. Hayashi T, Morohashi H, Hatakeyama M: Bacterial EPIYA effectors - where do they come from? What are they? Where are they going? Cell Microbiol 2013, 15:377-385.

45. Rikihisa Y, Lin M, Niu H: Type IV secretion in the obligatory intracellular bacterium Anaplasma phagocytophilum. Cell Microbiol 2010, 12:1213-1221.

46. Rikihisa Y, Lin M: Anaplasma phagocytophilum and Ehrlichia chaffeensis type IV secretion and Ank proteins. Curr Opin Microbiol 2010, 13:59-66.

47. IJdo JW, Carlson AC, Kennedy EL: Anaplasma phagocytophilum AnkA is tyrosine-phosphorylated at EPIYA motifs and recruits SHP-1 during early infection. Cell Microbiol 2007, 9:1284-1296.

48. Furuta Y, Yahara K, Hatakeyama M, Kobayashi KS: Evolution of cagA oncogene of Helicobacter pylori through recombination. PLoS One 2011, 6:e23499.

49. Al-Khedery B, Lundgren AM, Stuen S, Granquist EG, Munderloh UG, Nelson CM, Alleman AR, Mahan SM, Barbet AF: Structure of the type IV secretion system in different strains of Anaplasma phagocytophilum. BMC Genomics 2012, 13:678.

50. Pluta S, Hartelt K, Oehme R, Mackenstedt U, Kimmig P: Prevalence of Coxiella burnetii and Rickettsia spp. in ticks and rodents in southern Germany. Ticks Tick Borne Dis 2010, 1:145-147.

doi:10.1186/1746-6148-9-235

Cite this article as: Majazki et al: Anaplasma phagocytophilum strains from voles and shrews exhibit specific ankA gene sequences. BMC Veterinary Research 2013 9:235. 